\title{
Optimization of Biogas Electrical Power Generation using Neuro-Fuzzy Controller
}

\author{
${ }^{1}$ Alor Michael Onyeamaechi, ${ }^{2}$ Araoye Timothy Oluwaseun and ${ }^{3}$ Okika Stephen Sunday \\ ${ }^{1}$ Department of Electrical and Electronics Engineering, Enugu State University of Science and Technology, \\ Enugu, Nigeria. \\ ${ }^{2}$ Department of Mechatronics Engineering, University of Nigeria Nsukka, Nigeria \\ ${ }^{3}$ Department of Electrical and Electronics Engineering, Enugu State University of Science and Technology, \\ Enugu, Nigeria. \\ timmy4seun@yahoo.com
}

\begin{abstract}
Biogas electrical power generation is a renewable energy which originated from biological materials. The technology design and model power system that predict and control the generation of biogas Electrical production. This research paper develops a Neuro-fuzzy controller model for generation of Biogas power production. A Neuro-fuzzy controller is design to the Biogas power system in order to improve the power quality delivery to the load. The set of 27 rules are written for proper training of biogas electrical data in the neural network. The training is used to control signal of the Biogas Power output of the system. The output of Neural Network unit is given as input to the de-fuzzification unit and the linguistic variables are converted back into the crisp form. Therefore the algorithm was designed to decide power supply to the load as to improve the performance of the biogas system using MATLAB/SIMULINK and Neuro-fuzzy model was developed for easy input of the data. The result shows that biogas electrical power output increased by $4.39 \mathrm{kw}$, which is $54.8 \%$ increase when Neuro-fuzzy controller is incorporated. The improvement in the system is due to the training of input parameters of the biogas generated. The result obtained shows that there is Real Power improvement in Biogas system when Neuro-fuzzy is incorporated in the system model.
\end{abstract}

Keywords: Biogas power generation, MATLAB/SIMULINK, Neuro-fuzzy controller, Renewable energy

\section{Introduction}

Biogas is an organic gas which is obtained from the biodegradation or decomposition of biological organic wastes from plants and animals under anaerobic condition by the action of bacteria [10].The biological organic materials, which can be recycled to produce biogas, are referred to as "Biomass". In Nigeria, quite a large number of biomass is produced daily. They vary from the actions of humans, natural cause (as in death of living organisms) and industrial activities. Most of these wastes are often disposed either into the water bodies or on the land thereby leading to environmental pollution. This pollution constitutes environmental hazards, which pose serious threat to the health of the inhabitants of the area, or habitat [4]. Nowadays, organic by-products, which were once referred to as "waste products", are no longer considered so. This is due to the advent of "effective waste transformational technology" which ensures 
Alor Michael Onyeamaechi, Araoye Timothy Oluwaseun and Okika Stephen Sunday; Optimization of Biogas

Electrical Power Generation using Neuro-Fuzzy Controller. Transactions on Machine Learning and Artificial Intelligence, Volume 7 No 6 December (2019); pp: 21-29

an effective reuse of the so called "wastes". Biogas is produced when the biomass is subjected to a threephase process in the digester. The processes involved in biogas production are hydrolysis, acid-forming and methane-forming phases. These processes are carried out in course with the actions of environmentally responsive microorganisms.

Biomass is source of renewable energy which produces biogas when subjected to anaerobic digestion. The biogas is then purified to produce the useful methane gas. With the pervasive decline in supply of fossil fuels and environmental threats posed by it around the world, the possible and effective solution lies in the embrace of renewable energy for sustainable growth [11].

\section{Review of Biogas Electricity Generation}

Reference [3] discovered a double-stage programming which combines the optimization that combines ILP and superiority-inferiority based fuzzy-stochastic programming for lasting renewable energy planning. Reference [8] analyzed many renewable energy situations in relation to various sustainability conditions. Reference [1] used a power system optimization algorithm to predict an annual peak load in a power system with an intention to abate the error connected to the estimated model parameters. The significance of utilizing modern optimization techniques for temporary energy planning is because of the presence of numerous uncertainties [5][6] Considering a case of large-scale penetration of renewable production, basically, the electric power system ought to possess a suitable medium of recompensing the adverse effects caused by the inconsistency and uncertainty of the availability of solar, wind and hydro energy. There is a number of optimization problems associated to energy generally, which requires optimization techniques, for example, the forecasting of energy demands applying artificial neural network [15],.

Reference [2] study a computational technique to produce electrical power effectively from renewable sources. The study modeled a fuzzy logic controller to improve biogas electrical power output by comparing the biogas electrical power output with fuzzy logic controller and biogas electrical power output without fuzzy logic controller. Reference [14] constructed a 50kW biogas digester that processed poultry dung to produce electricity in order to supply electric power to the poultry farm and to the remote communities around on a commercial basis. Wastes from 50000 chickens were gathered, weighing about five tons which is capable of producing $40-80 \mathrm{~m}^{3} / \mathrm{hr}$ gas. This volume of gas can conveniently supply a $50 \mathrm{~kW}$ biogas generator. The effective life span of the digester is approximately 20 years and the returnon-investment time 5 years. The Net Present Value (NPV) was discovered to be positive and the internal rate of return, $19 \%$.

\subsection{Adaptive Neuro-Fuzzy Inference System (ANFIS)}

Adaptive Neuro-Fuzzy Inference System (ANFIS) is an Artificial Intelligence technique which creates a fuzzy inference system based on the input-output model data pairs of the system. ANFIS combines neural network and fuzzy system together. ANFIS can be employed in a wide variety of applications of modelling, decision making, signal processing and control. ANFIS is a class of adaptive network that is functionally equivalent to Fuzzy Inference System. Since ANFIS design starts with the pre-structured system, the membership function of input and output variables contain more information that Neural Network has to drive from sampled data sets. Knowledge regarding the systems under design can be used right from the start. Hence, the proposed ANFIS controller is more efficient. The rules are in the 
linguistic forms and so intermediate results can be analyzed and interpreted easily [12]. ANFIS is a multilayer adaptive neural network based Fuzzy Inference System. ANFIS algorithm is composed of fuzzy logic and neural networks with 5 layers to implement different node functions to learn and tune parameters in a Fuzzy Inference System (FIS) structure using a hybrid learning mode. In the forward pass of learning, with fixed premise parameters, the least squared error estimate approach is employed to update the consequent parameters and to pass the errors to the backward pass. In the backward pass of learning, the consequent parameters are fixed and the gradient descent method is applied to update the premise parameters. Premise and consequent parameters will be identified for membership function (MF) and FIS by repeating the forward and backward passes. ANFIS is fuzzy Sugeno model put in the framework of adaptive systems to facilitate learning and adaption [7]. Such framework makes Fuzzy Logic Controller more systematic and less relying on expert knowledge [13].

To present the ANFIS architecture, let us consider two fuzzy rules based on a first order sugeno model:

Rule 1: IF ( $x$ is $A 1)$ and ( $y$ is $B 1)$ THEN ( $f 1=p 1 x+q 1 y+r 1)$

Rule 2: IF ( $x$ is $A 2)$ and ( $y$ is $B 2)$ THEN ( $f 2=p 2 x+q 2 y+r 2)$

where $x$ and $y$ are the inputs, $\mathrm{Ai}$ and $\mathrm{Bi}$ are the fuzzy sets, $\mathrm{fi}$ are the outputs within the fuzzy region specified by the fuzzy rule, pi, qi and ri are the design parameters that are determined during the training process.

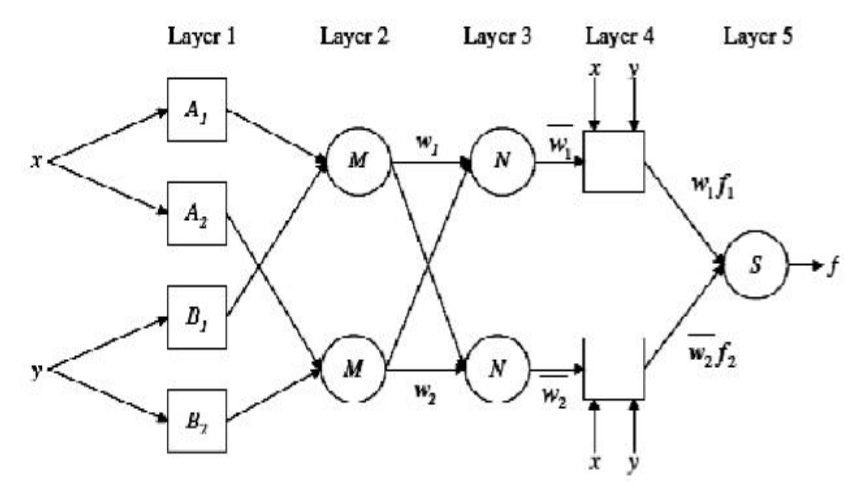

Figure1 ANFIS architecture [9]

\section{Materials and Method}

The paper design micro-biogas generator controller of methane gas for the generation of Power production using ANFIS controller. The fuzzification unit converts the crisp data into linguistic variables, which is given as input to the rule based block. There are three inputs and three membership function for each input and output in the simulation of nonlinear, which gives 33 . Therefore set of 27 rules are written for proper training of biogas electrical data in the neural network. The training is used to control signal of the Biogas Power output of the system. The output of Neural Network unit is given as input to the de-fuzzification unit and the linguistic variables are converted back into the crisp form. Therefore the algorithm was designed to decide power supply to the load as to improve the performance of the biogas system using MATLAB/SIMULINK and Neuro-fuzzy model was developed for easy input of the data. The improvement of Biogas power generation steps using ANFIS are:

- Develop the simulink model for LFC and BPC of Biogas power system with TakagiSugeno inference model Fuzzy Logic Controller. 
- Simulate the Simulink model with membership function for three inputs.

- Train the Biogas Experimental data and simulating with fuzzy Logic Controller in other to design ANFIS.

- Train the collected data with generated FIS up to 100 Epochs.

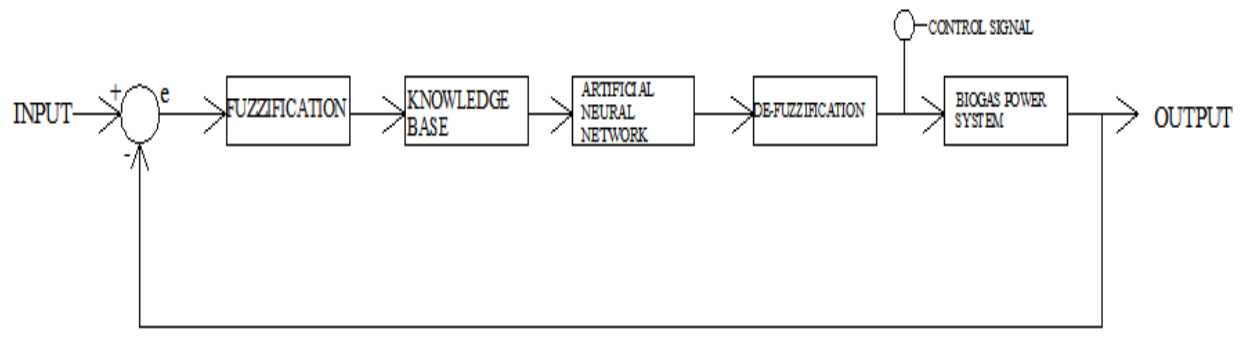

Figure 2: ANFIS Biogas Power Neuro-Fuzzy Controller

\subsection{Mathematical Modeling of Biogas Digester}

A total $150 \mathrm{~kg}$ mass of manure was considered for generating Electric Power. The simulation and Analysis was performed by using MATLAB 2007 SOFTWARE TOOLBOX to carry out calculations to obtain the Power output in the Community. The program automatically calculates the volume of the digester required in generating electric energy and the Power generated.

The mass of dry solid in waste is given by:

$$
\mathrm{M}_{0}=\mathrm{N}_{\mathrm{a}} \mathrm{C}_{\mathrm{w}}
$$

The volume of Biogas is given by:

$$
V_{\mathrm{b}}=\mathrm{Rm}_{0}
$$

The volume of fluid in the digester is given by:

$$
v_{f}=\frac{m_{0}}{\rho_{m}}
$$

The volume of the digester is given by:

$$
V_{d}=V_{f} t_{r}
$$

Energy generated is given as:

$$
E=\eta H_{\mathrm{b}} V_{\mathrm{b}}
$$

Where $H_{\mathrm{b}}$ is the heat of combustion per unit volume biogas, $\eta$ is the combustion efficiency of burners. Where $R$ is the biogas yield per unit dry mass of whole input $0.2-0.4 \mathrm{~m}^{3} \mathrm{~kg}^{-1}$ and $\mathrm{M}_{0}$ is the mass of manure input. Where $V_{\mathrm{f}}$ is the flow rate of the digester fluid and $t_{\mathrm{r}}$ is the retention time in the digester. Where $\rho_{m}$ is the density of dry matter in the fluid. Where $\mathrm{N}_{\mathrm{a}}$ is the number of animals that produced the dung and $\mathrm{C}_{\mathrm{w}}$ the solid in waste per animal per day/kg 


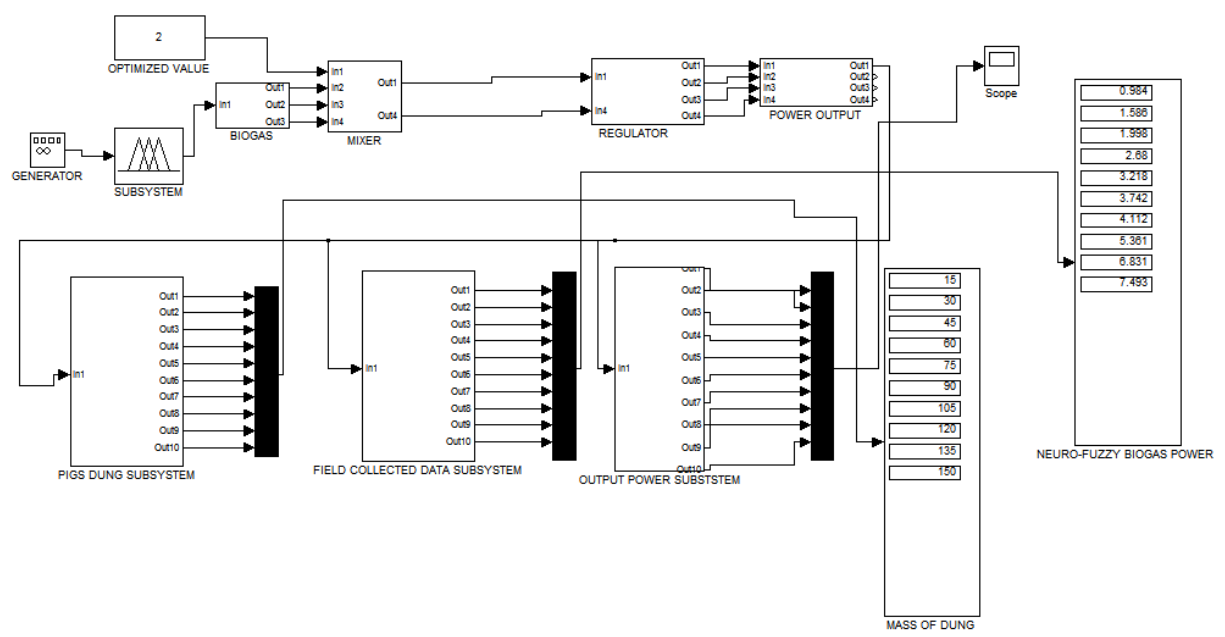

Figure 3: SIMULINK model of Neuro-fuzzy controller.

\section{$4 \quad$ Result and Discussion}

The simulation results are presented according to biogas electrical power output without and with Neurofuzzy controller for different Operational Time and mass of dung.

Figure4 shows ANFIS Architecture of Neuro-fuzzy controller for Biogas power generation. The result of Biogas electrical power training using MATLAB is shown below:

ANFIS info:

Number of nodes: 78

Number of linear parameters: 108

Number of nonlinear parameters: 36

Total number of parameters: 144

Number of training data pairs: 10

Number of checking data pairs: 0

Number of fuzzy rules: 27

Start training ANFIS.

$1 \quad 0.36081$

$2 \quad 0.352517$

Figure5 shows Fuzzy sugeno model Rule editor. The model contain 3linguistic input variable with triangular membership function which produced 27 rules.

Figure6 shows Biogas electrical power operational time without Neuro-fuzzy controller. The result shows that the values of biogas electrical power output with Neuro-fuzzy controller for $1 \mathrm{hr}, 2 \mathrm{hr}, 3 \mathrm{hr}, 4 \mathrm{hr}, 5 \mathrm{hr}$, $6 \mathrm{hr}, 7 \mathrm{hr}, 8 \mathrm{hr}, 9 \mathrm{hr}$ and $10 \mathrm{hr}$ operational time are $0.46 \mathrm{~kW}, 0.98 \mathrm{~kW}, 1.47 \mathrm{~kW}, 1.97 \mathrm{~kW}, 2.48 \mathrm{Kw}, 2.96 \mathrm{kw}$, $3.478 \mathrm{kw}, 3.93 \mathrm{kw}, 4.487 \mathrm{kw}$ and $4.978 \mathrm{~kW}$ respectively. The result show that the greater the operational time of Biogas plant, the greater Power generated. Figure7 shows the relationship between mass of dung and biogas electrical real power with and without Neuro-fuzzy controller. The result shows that the values of biogas electrical power output without Neuro-fuzzy controller for $15 \mathrm{~kg}, 30 \mathrm{~kg}, 45 \mathrm{~kg}, 60 \mathrm{~kg}, 75 \mathrm{~kg}, 90 \mathrm{~kg}$, $105 \mathrm{~kg}, 120 \mathrm{~kg}, 135 \mathrm{~kg}$ and $150 \mathrm{~kg}$ operational time are $0.46 \mathrm{~kW}, 0.98 \mathrm{~kW}, 1.47 \mathrm{~kW}, 1.97 \mathrm{~kW}, 2.48 \mathrm{Kw}, 2.96 \mathrm{kw}$, $3.478 \mathrm{kw}, 3.93 \mathrm{kw}, 4.487 \mathrm{kw}$ and $4.978 \mathrm{~kW}$ respectively. The values of biogas electrical power output with Neuro-fuzzy controller for $15 \mathrm{~kg}, 30 \mathrm{~kg}, 45 \mathrm{~kg}, 60 \mathrm{~kg}, 75 \mathrm{~kg}, 90 \mathrm{~kg}, 105 \mathrm{~kg}, 120 \mathrm{~kg}, 135 \mathrm{~kg}$ and $150 \mathrm{~kg}$ operational time are $0.984 \mathrm{kw}, 1.586 \mathrm{kw}, 1.998 \mathrm{kw}, 2.68 \mathrm{kw}, 3.218 \mathrm{kw}, 3.742 \mathrm{kw}, 4.112 \mathrm{kw}, 5.361 \mathrm{kw}, 6.831 \mathrm{kw}, 7.493 \mathrm{kw}$ 
Alor Michael Onyeamaechi, Araoye Timothy Oluwaseun and Okika Stephen Sunday; Optimization of Biogas Electrical Power Generation using Neuro-Fuzzy Controller. Transactions on Machine Learning and Artificial Intelligence, Volume 7 No 6 December (2019); pp: 21-29

respectively. This insinuates that the real power of Biogas electrical plant increases with increase in mass of dung when Neuro-fuzzy controller is incorporated into the system. Figure8 shows the comparison of volume $f$ Biogas for Electrical power generation without and with Neuro-fuzzy controller. The values of Volume of Biogas and Biogas Real power without Neuro-fuzzy controller are 3.6m3, 7.2m3, 10.8m3, $14.4 \mathrm{~m} 3,18 \mathrm{~m} 3,21.6 \mathrm{~m} 3,25.2 \mathrm{~m} 3,28.8 \mathrm{~m} 3,32.4 \mathrm{~m} 3,36 \mathrm{~m} 3$ and $0.46 \mathrm{~kW}, 0.98 \mathrm{~kW}, 1.47 \mathrm{~kW}, 1.97 \mathrm{~kW}, 2.48 \mathrm{Kw}$, $2.96 \mathrm{kw}, 3.478 \mathrm{kw}, 3.93 \mathrm{kw}, 4.487 \mathrm{kw}$ and $4.978 \mathrm{~kW}$ respectively. Also the value of volume of Biogas and Biogas Real power with Neuro-fuzzy controller are 3.6m3, 7.2m3, 10.8m3, 14.4m3, 18m3, 21.6m3, $25.2 \mathrm{~m} 3,28.8 \mathrm{~m} 3,32.4 \mathrm{~m} 3,36 \mathrm{~m} 3$ and $0.984 \mathrm{kw}, 1.586 \mathrm{kw}, 1.998 \mathrm{kw}, 2.68 \mathrm{kw}, 3.218 \mathrm{kw}, 3.742 \mathrm{kw}, 4.112 \mathrm{kw}$, $5.361 \mathrm{kw}, 6.831 \mathrm{kw}, 7.493 \mathrm{kw}$ respectively. Hence, the volume of Biogas that will generate power in a thermal engine at different mass of dung are $3.6 \mathrm{~m} 3,7.2 \mathrm{~m} 3,10.8 \mathrm{~m} 3,14.4 \mathrm{~m} 3,18 \mathrm{~m} 3,21.6 \mathrm{~m} 3,25.2 \mathrm{~m} 3$, $28.8 \mathrm{m3}, 32.4 \mathrm{~m} 3,36 \mathrm{~m} 3$ and $15 \mathrm{~kg}, 30 \mathrm{~kg}, 45 \mathrm{~kg}, 60 \mathrm{~kg}, 75 \mathrm{~kg}, 90 \mathrm{~kg}, 105 \mathrm{~kg}, 120 \mathrm{~kg}, 135 \mathrm{~kg}, 150 \mathrm{~kg}$ respectively. These shows that the greater the mass of dung, the greater the Volume of Biogas produced to generate electricity. Finally, there is linear relationship between mass of dung, volume of Biogas and biogas electrical power output when Neuro-fuzzy controller is incorporated.

The result shows that biogas electrical power output increased by $4.39 \mathrm{kw}$, which is $54.8 \%$ increase with introduction of Neuro-fuzzy controller. The improvement in the system is due to the training of input parameters of the biogas generated. The result obtained shows that there is Real Power improvement in Biogas system when Neuro-fuzzy is incorporated in the system model.

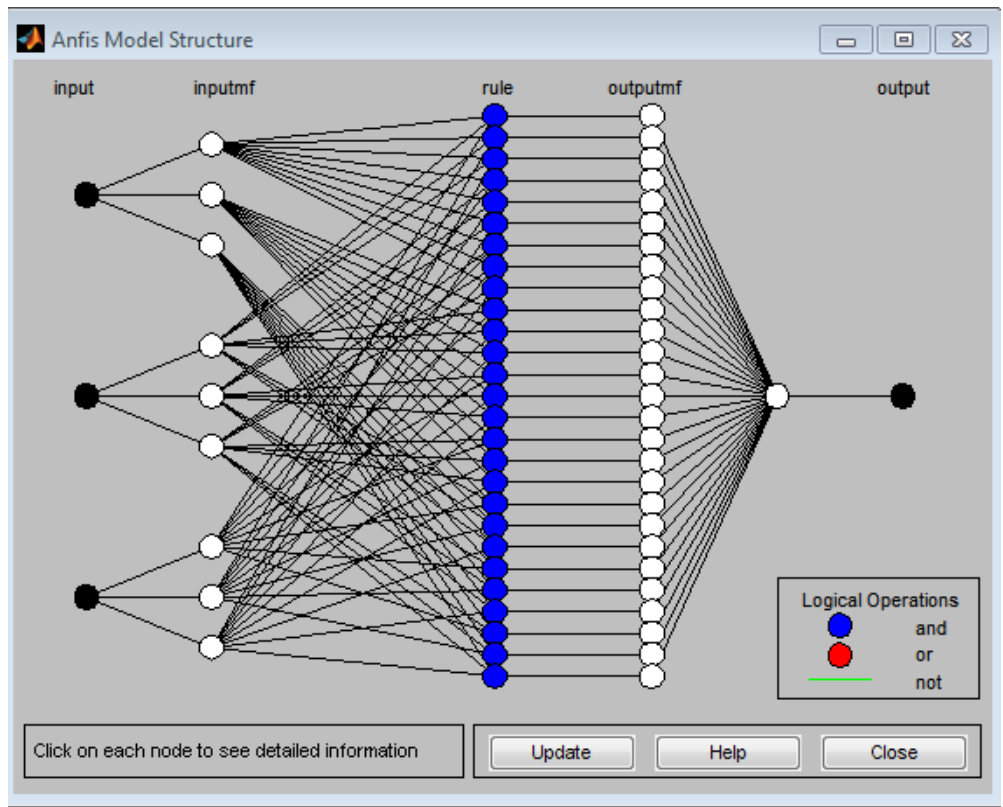

Figure 4: ANFIS Architecture of Neuro-fuzzy controller for Biogas power generation. 
Rule Editor: Biogas_Power_Plant

17. If (input1 is Medium) and (input2 is High) and (input 3 is Medium) then (output is out1 mf17) (1)

18. If (input1 is Medium) and (input2 is High) and (input 3 is High) then (output is out $1 \mathrm{mf} 18$ ) (1)

19. If (input1 is High) and (input2 is Low) and (input3 is Low) then (output is out $1 \mathrm{mf19}$ ) (1)

20. If (input 1 is High) and (input 2 is Low) and (input 3 is Medium) then (output is out $1 \mathrm{mf} 20$ ) (1)

21. If (input1 is High) and (input2 is Low) and (input 3 is High) then (output is out $1 \mathrm{mf} 21$ ) (1)

22. If (input1 is High) and (input 2 is Medium) and (input3 is Low) then (output is out $1 \mathrm{mf} 22$ ) (1)

23. If (input1 is High) and (input2 is Medium) and (input 3 is Medium) then (output is out1 mf23) (1)

24. If (input1 is High) and (input2 is Medium) and (input3 is High) then (output is out $1 \mathrm{mf} 24$ ) (1)

25. If (input1 is High) and (input2 is High) and (input3 is Low) then (output is out $1 \mathrm{mf} 25$ ) (1)

26. If (input1 is High) and (input 2 is High) and (input 3 is Medium) then (output is out1 $\mathrm{mf} 26$ ) (1)

27. If (input1 is High) and (input2 is High) and (input 3 is High) then (output is out1 mf27) (1)

If

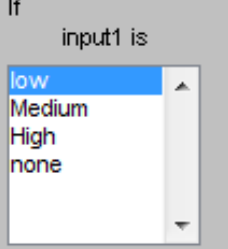

and

input 2 is

and

input 3 is

Then

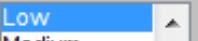

Medium

High

none

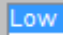

Low

High

$\square$ not

$+$

none

$\square$ not

Weight:

[ Connection

or

C) and

Figure 5: Fuzzy sugeno model Rule editor

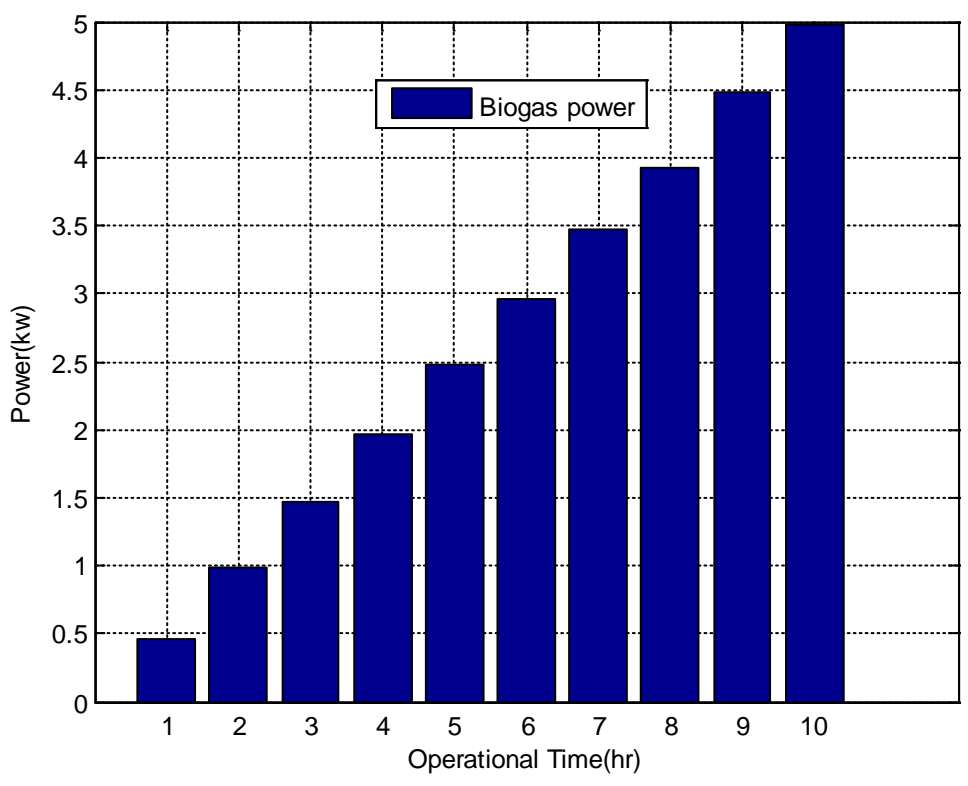

Figure 6: Biogas power generation with different operational time. 


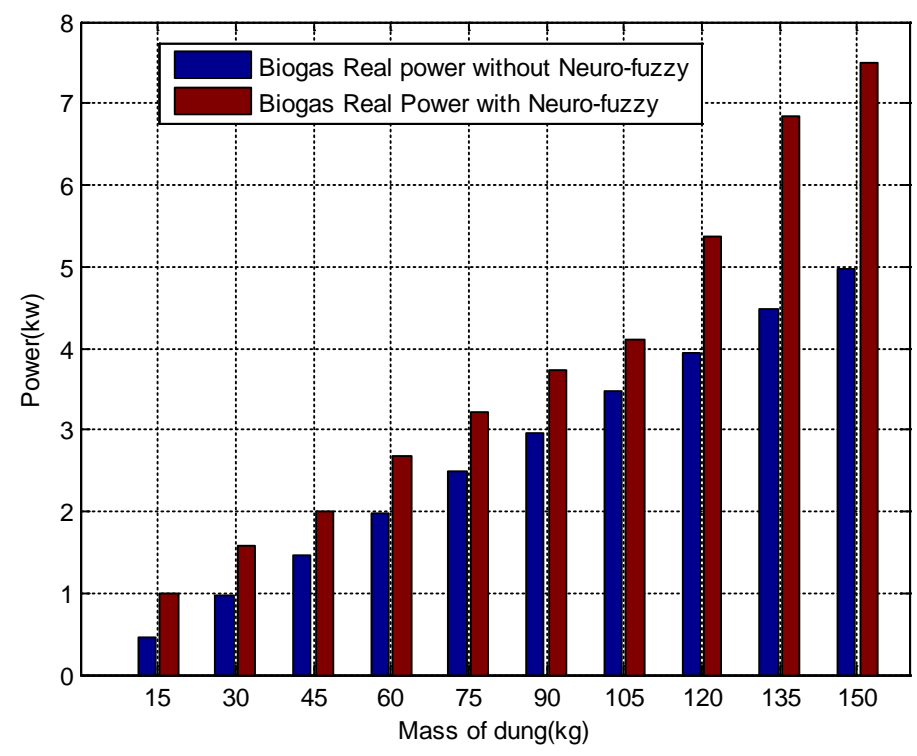

Figure 7: Comparison of Biogas Real power with and without Neuro-fuzzy controller.

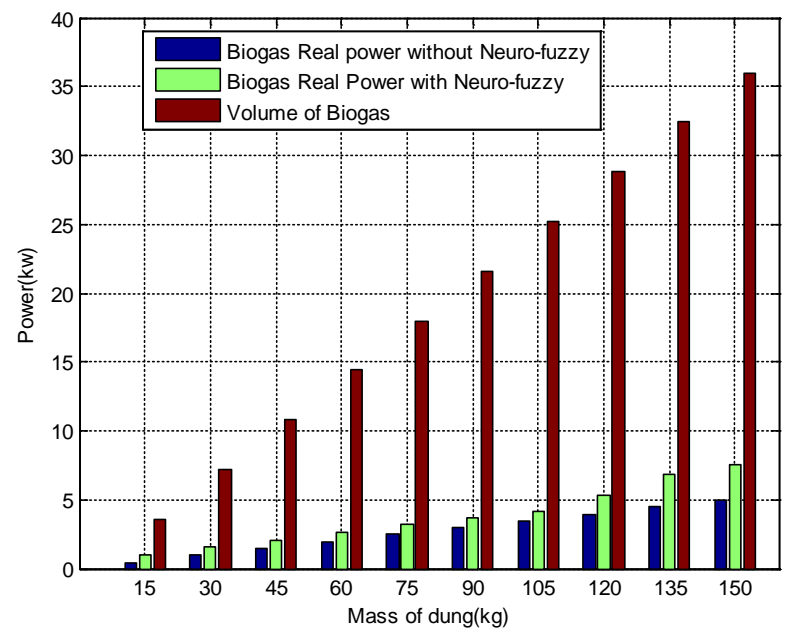

Figure8: Comparison of volume of Biogas for Electrical power generation without and with Neuro-fuzzy controller.

\section{Conclusion}

This research paper has developed computational intelligence for improving Biogas Electrical Power generation. The study modeled a Neuro-fuzzy controller to improve biogas electrical power output by comparing the biogas electrical power output without Neuro-fuzzy controller and biogas electrical power output with Neuro-fuzzy controller. The set of 27 rules are written for proper training of biogas electrical data in the neural network. The training is used to control signal of the Biogas Power output of the system. Thus, the algorithm was designed to improve the performance of the biogas system using MATLAB/SIMULINK and Neuro-fuzzy model was developed for easy input of the data. Finally the result shows that biogas electrical power output increased by $4.39 \mathrm{kw}$, which is $54.8 \%$ increase with introduction of Neuro-fuzzy controller. The improvement in the system is due to the training of input parameters of 
the biogas generated. The result obtained shows that there is Real Power improvement in Biogas system when Neuro-fuzzy is incorporated in the system model.

\section{REFERENCE}

[1] AlRashidi MR, EL-Naggar KM (2010). Long term electric load forecasting based on particle swarm optimization. Applied Energy 2010; 87(1):320-6.

[2] Araoye Timothy Oluwaseun, C.A. Mgbachi, Ganiyu Adedayo Ajenikoko(2018). Development of a fuzzy logic technique for biogas generation of electrical energy: international journal of Advanced Scientific and Technical Research.

[3] Cai YP, Huang GH, Tan Q, Yang ZF (2009). Planning of community-scale renewable energy Management systems in a mixed stochastic and fuzzy environment. Renewable Energy 2009; 34(7):1833-47.

[4] Ezeonu FC (2002), Nigerian journal of Energy.PP 53 - 57.

[5] Fleten S.E, Maribu K.M, WangensteenI(2007). Optimal investment strategies in decentralized renewable power generation under uncertainty. Energy 2007; 32(5):803-15.

[6] Hiremath RB, Shikha S, RavindranathNH(2007). Decentralized energy planning; modeling and application-a review. Renewable and Sustainable Energy Reviews 2007;11(5):729-52.

[7] Jang, JSR. ANFIS: Adaptive network based fuzzy inference system. IEEE Transactions on systems, Man, and, Cybernetics 1993. 23(3): 665-685 <https://doi.org/10.1109/21.256541>

[8] Kowalski K, Stagl S, Madlener R, OmannI(2009). Sustainable energy futures: methodological challenges in combining scenarios and participatory multi-criteria analysis. European Journal of Operational Research 2009; 197(3):1063-74.

[9] Laouafi A, Mordjaoui M, Dib D. One-Hour Ahead Electric Load Forecasting Using Neuro-fuzzy System in a Parallel Approach. In: Azar AT, Vaidyanathan S, editors. Computational Intelligence

[10] Mahin, D.B. (1982) Biogas in Developing Countries. Bioenergy System Report to USAID, Washington, DC.

[11] Ofoefule, Akuzuo U et al (2010)Adv. Appl. Sci. Res.,1 (3):98-105

[12] Sumathi S, Surekha P. Computational intelligence paradigms theory and applications using MATLAB.

[13] Taylor and Francis Group, LLC, 2010. Applications in Modeling and Control, Cham, Switzerland: Springer International Publishing, 2015. pp. 95-121.

[14] WahiduzzamanSajib, Mehadi Hassan, NajmulHoque, Mourshed M(2018).."Electricity Generation from Poultry Waste in Bangladesh" January 2018.

[15] Yokoyama R, Wakui T, SatakeR(2009). Prediction of energy demands using neural network with model identification by global optimization. Energy Conversion and Management 2009;50:319-27. 